\title{
System Analysis for the Traceability and Logistics Management of Fresh Agricultural Products Supply Chain
}

\author{
Yu-Chuan LIU \\ Department of Information Management \\ Tainan University of Technology \\ Tainan, Taiwan \\ E-mail: t00258@mail.tut.edu.tw
}

\author{
Hong-Mei GAO \\ Department of Economic Management \\ Tianjin Agricultural University \\ Tianjin, China \\ E-mail: gaohongmei@126.com
}

\begin{abstract}
Issues and concerns for food safety, agro-processing, and the environmental and ecological impact of food production have been attracted many research interests. Traceability and logistics management of fresh agricultural products is faced with the technological challenges including food product label and identification, activity/process characterization, information systems for the supply chain, i.e., from farm to table. Application of information technologies for food processing and logistics industry in the fields of smart packaging and materials, automation and control technology, standards and their application scenarios, and production management principles were wildly studied. A collaborative research project for the supply and logistics of fresh agricultural products in Tianjin was performed. System analysis for the logistics management information system is studied. The model-driven business transformation, an approach uses formal models to explicitly define the structure and behavior of a business, is applied for the review and analysis process. Specific requirements for the logistics management solutions are proposed. Development of this research is crucial for the solution integration of supply and logistics management information system for fresh agricultural products.
\end{abstract}

Keywords-component; logistics management information system; fresh agricultural products; model-driven business transformation

\section{INTRODUCTION}

The heightened awareness of food-related safety issues among food consumers drives the demand for more information about the vertical food supply chain about the origin and handling of the basic commodities and food products generated and consumed throughout the world. Developments of agro-food industries are facing global challenges that can only be supported by information technologies. The major IT development lines, the support potential of their integration, organizational requirements for the utilization, and possible consequences for the future organization of the agro-food sector were reviewed [1]. Traceability is an essential subsystem of quality management, and must be managed by setting up a traceability system, which keeps the data tracking of product routes and of selected attributes. A traceability system can consist two elements, the routes of the product, path along which products can be identified throughout the manufacturing, distribution and retail procedures, and the extent of traceability wanted [2]. Food traceability requires that all stakeholders within the food supply chain, including agriculture and feed producers, food manufacturers, retailers, etc., must be able to identify the source of all raw materials and ingredients to whom the products have been sold. The food companies must apply identification systems and data handling procedures and these must be integrated into their quality management system. The sector encompassing information technology (IT) centers ought to find a reasonable compromise between the simple, step by step passing of traceable unit IDs for the neighboring actors, and the accumulated enormously huge databases of the actors. The traceability system is to provide services for the supply chain actors on cooperative basis of the mutual interests [3]. In addition, the IT centers must support the supply chain and value chain management, as well as the work of the authorities that are responsible for the human health. Opara [4] reviewed the concepts of supply chain management and traceability in agriculture and highlighted the technological challenges, including food product label and identification, activity/process characterization, information systems for data capture, analysis, storage and communication, and the integration of the overall traceable supply chain in implementing traceable agricultural supply chains. Wang et al. [5] addressed that the values on traceability can be integrated with the supply chain management processes to manage the business process and improve its performance. Bosona and Gebresenbet [6] summarized the literature review on the food traceability issues. The definition, driving forces, barriers, benefits, traceability technologies, improvements, and performances of food traceability system had been discussed. It was pointed out that the development of full chain food traceability system is quite complex in nature, and a deeper understanding of real processes from different perspectives such as economic, legal, technological, and social issues are essential. Consequently, studies on the integration of traceability activities with food logistics activities, the linkage between traceability system and food manufacturer, standardization of data capturing and communication protocol for different drivers, and performance evaluation frameworks for food traceability system need to be focused. 
A new model and prototype of a new Farm Information Management System, which meets the changing requirements for advising managers with formal instructions, recommended guidelines and documentation requirements for various decision making processes, was developed [7]. As achieving end-to-end traceability across the supply chain is quite a challenge from a technical, a co-ordination and a cost perspective, Kelepouris et al. [8] suggested a radio frequency identification (RFID) technology and outlined both information data model and system architecture that made traceability feasible and easily deployable across a supply chain. Based on an integration of alphanumerical codes and RFID technology, the traceability system for Parmigianino Reggiano (the famous Italian cheese) was developed [9]. Manthou et al. [10] provided empirical insights regarding the use of Internet-based applications in the agri-food supply chain by focusing on the Greek fruit canning sector. The companies' perceptions regarding perceived benefits, constrained factors and motivation factors towards the use of
Internet-based applications were studied. A PDA-based Record-keeping and Decision-support System for traceability in cucumber production was developed on Windows Mobile platform invoking a Geographic Information System (GIS) control [11]. Two agricultural production enterprises were chosen as case study to evaluate the system and the results show that the efficiency of production record-keeping and decision-support is improved by the simple and friendly system. The state-of-the-art review in the recent advancements of food processing and packaging industry in the fields of smart packaging and materials, automation and control technology, standards, and their application scenarios, and production management principles and their improvements was proposed [12].

The logistics and information flow play an important role in the fresh agricultural products supply chain. The purpose of this research is to further provide a complete study on the

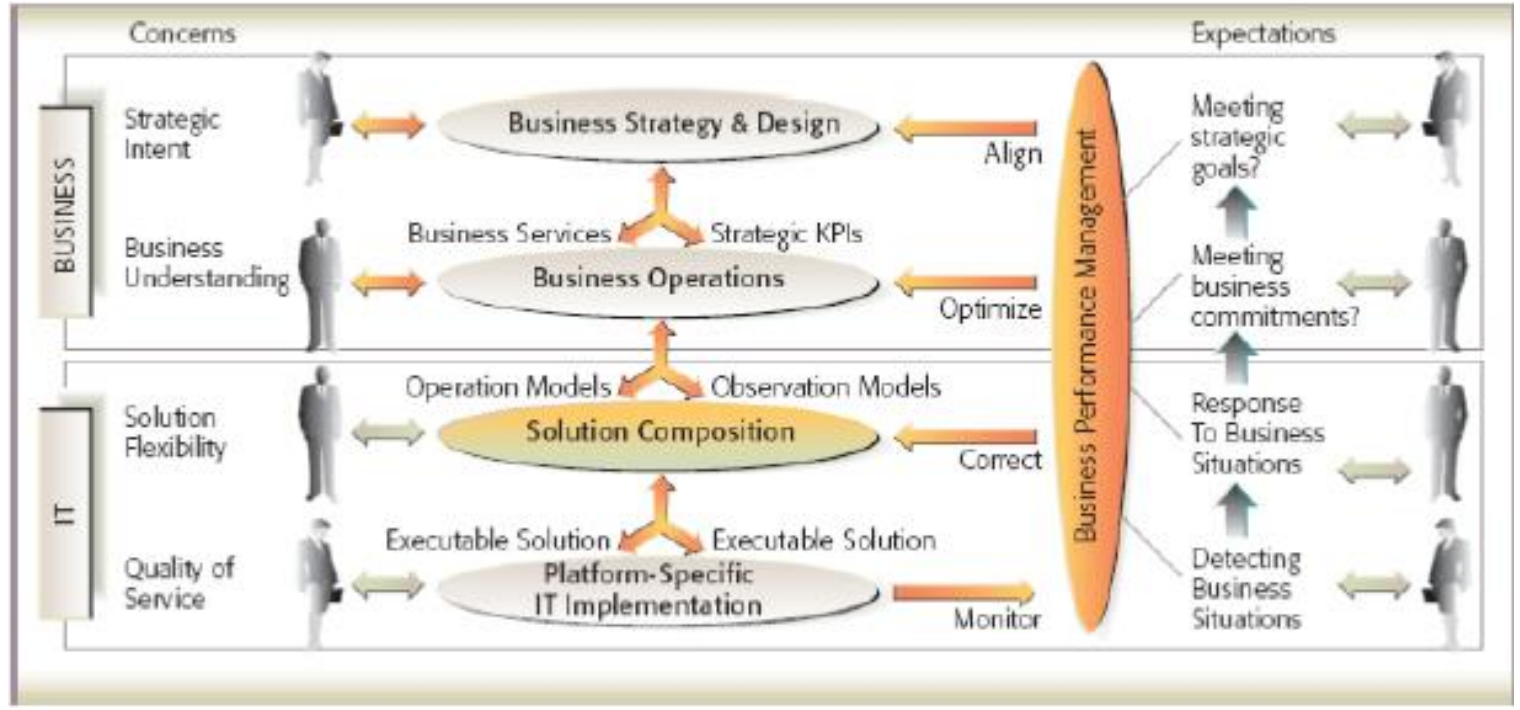

Figure 1. Model-driven business transformation framework, from [14]

Issues and solutions for the logistics and information management of fresh agricultural products. A full life-cycle business-to-technology method, model-driven business transformation MDBT [13], is both a business transformation methodology and a set of innovative technologies that allow business strategies to be realized by choreographing workflow tools and human activities. MDBT uses formal models to explicitly define the structure and behavior of a business component. Kumaran et al [14] presented a new approach to IT service workflow automation and a new generation of Service-delivery management systems based on the modeldriven transformational approach and service-oriented architecture. The MDBT approach is applied to propose an integrated solution. Development of this research is crucial for the solution integration of information and logistics management in fresh agricultural products supply chain business.

\section{MODEL-DRIVEN BUSINESS TRANSFORMATION APPROACH}

Model-driven business transformation, MDBT developed by IBM research, uses formal models to explicitly define the structure and behavior of a business component. These models can be employed to monitor, analyze, and improve its performance, and leverages these models in the construction of its IT systems. The framework is made up of four layers: business strategy, business operations, solution composition, and IT implementation. Each layer constitutes a different level of abstraction, performs a well-defined function, and has a different audience. The strategy layer defines the goals and objectives of the business system. The operation layer describes the operations performed by the business system to achieve the goals. The composition layer is an abstraction of the computational elements that are needed to execute the business operations. The implementation layer specifies how the computational elements are implemented on a specific IT 
platform. Figure 1 shows the MDBT framework, including the separation of concerns, connections between model layers, and the closed-loop architecture achieved using the business process modeling component.

In the MDBT approach, the transformation process begins with the identification of the strategic goals and objectives of the business component. This leads to a set of initiatives that support these goals. These initiatives determine the definition, analysis, optimization, and implementation of the business operations of the organization such that the strategic goals can be achieved. Formal definition of the business operations and the operational KPIs (key performance indicators) is the next step of transformation process which was referred as the

Business operation model. A business operation model is different from the more familiar workflow models. A business operation model, on the other hand, defines the key business artifacts and the operations performed on these artifacts. The third step of solution composition in MDBT is the judicious use of technology to support the execution of business operations. This involves the generation of a platformindependent solution composition model and the realization of this model on a specific software platform. The final step in MDBT is to create an implementation of the IT solution on a specific IT platform. Once the solution is deployed, business owners can monitor and analyze business performance using KPIs and continuously improve the models, both at the business and IT levels, based on this performance analysis.

\section{SOLUTION REQUiREMENTS ANALysis By MDBT}

By applying MDBT approach, the definition of goals and objectives should be firstly analyzed in strategy layer. As the authors reviewed the current fresh agricultural products supply chain in Tianjin, the first two issues of the product loss during the logistics procedure and cost (and/or effectiveness) of the cold chain logistics. The infrastructure of the fresh agricultural products logistics management can be summarized as shown in Fig. 2. The customer relationship management (CRM) and the collaborative planning, forecasting, and replenishment (CPFR) are the two major solutions to overcome the highly uncertain property of the supply and demand for fresh agricultural products. Traceability information of the contract farming is required during the farming process. The farming information integration is necessary if the products are supplied from the supply chain farmers. The logistics information during the transportation and storage for all the supply chain stages to ensure the completeness of the traceability management is important and necessary. The objectives of the fresh agricultural products supply chain logistics information are consequently to improve the effectiveness and efficiency for the fresh agricultural products logistics management system

The KPIs for hardware protection can be fresh agricultural products loss during transportation, handling, and storage procedures. The KPIs for the software management can be the easy and complete access of the traceability data through the whole supply chain process, i.e., the farming data, process and ingredient information, the transportation and storage environment condition histories.

The second step of business operation analysis for MDBT is to perform the business operation. Considering the supply chain process shown in Fig. 2, some observations can be made:

- End customers can receive the fresh agricultural products via an $\mathrm{O} 2 \mathrm{O}$ scenario directly from the ecommerce provided by the agricultural corporations. The transportation procedures can be minimized so that the product loss caused can also be reduced.

- The $\mathrm{O} 2 \mathrm{O}$ scenario also provides an optimized product combinations both for the customer and supplier. The products delivered can be optimized according to the farming production condition and the customers' order requirement. The balance of the supply and demand can be optimized and the effectiveness of farming production can be improved.

- The fresh agricultural products can be supplied form both the contract farmers with close farming auditing, and from supply chain farmed with loose farming control and/or monitoring. Traceability information should be guaranteed no matter who supplies.

Detail solution requirements are further studied through the supply chain processes. Figure 3 shows that the logistics information management platform between the supplies chain enterprises that can be shared and integrated for further enhancement of the supply chain management efficiency. The information system must be designed to cope with the intricate farming data, the rigmarole product transportation and storage information requirements. The platform independent solution requirements are proposed in this paper. The information system should cover the farming, and logistics of the supply chain process.

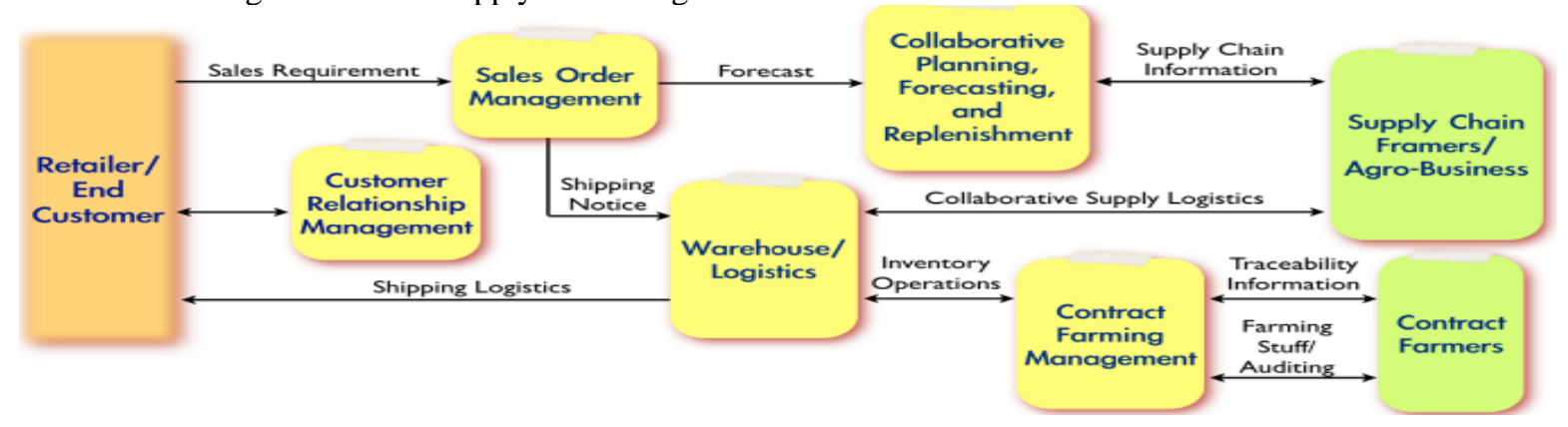

Figure 2. Infrastructure of the fresh agricultural products logistics management. 


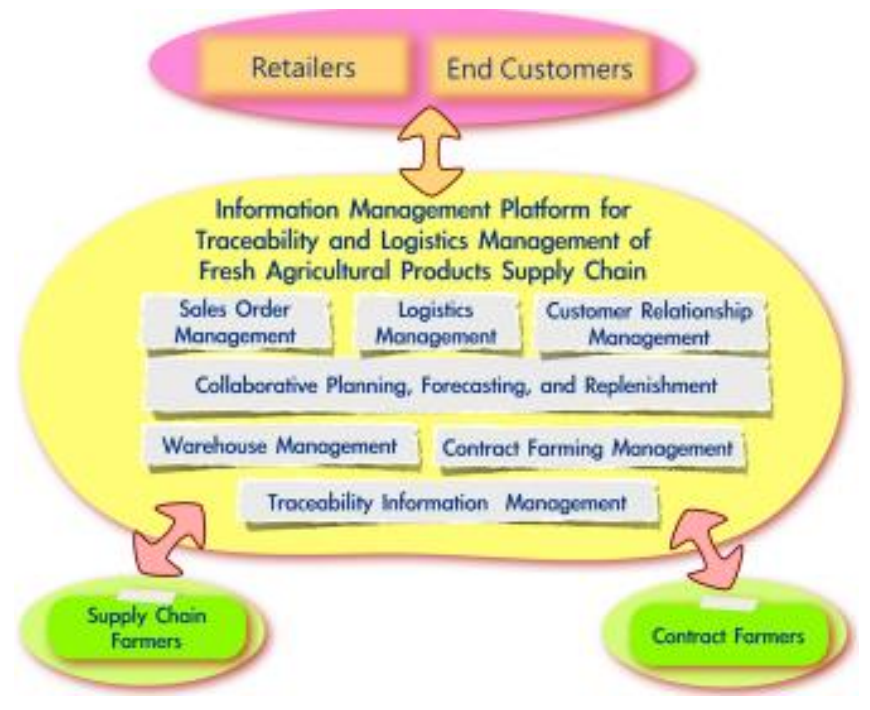

Figure 3. Systematic diagram for the information management platform for traceability and logistics management of the fresh agricultural products supply chain.

The specific functional requirements from configuration management analysis include:

\section{A. Traceability Data Information Management}

Food traceability can be found mostly by attaching a 2dimensional label, QR (quick response) code is the usual case, on the package of the food or agro-products. A mobile farming information system to collect the farming data and directly transmitted to the traceability system by cell phone and two dimensional codes was proposed in [15]. The basic traceability information is consisted of the farmer, cropland, and crop planted. All the farming activities are performed on the cropland. The farming activities can be divided into three categories:

- $\quad$ Farming operations for all kind of crops like seeding and pruning without the need of further attribute records.

- Fertilizing operations which the fertilizer and amount used need to be recorded.

- Disease prevention operations with the use and records of pesticides.

All the required operations are encoded into QR codes. Different fertilizers and pesticides are all encoded into distinct QR code. By scanning the proper $\mathrm{QR}$ code, the farmer can easily upload the operation messages into the data collection system. As the usage of pesticide is critical for the pesticide residual can be harmful to human, the relationship of allowable pesticide for crop is constructed to guarantee that safety of pesticide usage. The basic traceability information is consisted of the farmer, cropland, and crop planted. All the farming activities are performed on the cropland. The farming activities can be divided into three categories: the farming operations for all kind of crops like seeding and pruning without the need of further attribute records; the fertilizing operations which the fertilizer and amount used need to be recorded; and the disease prevention operations with the use and records of pesticides. All the required operations are encoded into QR codes and every farming operation is transformed into distinct QR code label. Different fertilizers and pesticides are all encoded into distinct QR code. By scanning the proper QR code, the farmer can easily upload the operation messages into the data collection system. As the usage of pesticide is critical for the pesticide residual can be harmful to human, the relationship of allowable pesticide for crop is constructed to guarantee that safety of pesticide usage.

\section{B. Information System Integration}

The system architecture for the integrated information management platform can be summarized as shown in Fig. 4 and followed.

- $\quad$ CPFR for the fresh agricultural products supply chain with the considerations of the farming production and the market requirements for proper farming control and products dispatching is necessary to minimize the unbalance of the supply-and-demand of fresh agricultural products.

- Detail analysis for the traceability information of contract and supply farmers is necessary to assure the software systems can achieve properly the control and traceability purpose.

- The warehouse management of fresh agricultural products is quite different from the general grocery items. The storage condition, labeling, and packing need to be carefully reviewed.

- The integrated platform consists of different venders of the supply chain, the effective interface definition and communication protocol design are crucial for the success of the information systems.

\section{Logistics Information Management}

Venders in the fresh agricultural products supply chain are usually located far away from food industries, retailer, and customers. Transportation of fresh agricultural products can be summarized in two manners. The first type is transported directly by the food industries (or agricultural corporations). The other is to be delivered by the third-party services such as DHL. The quality of transportation and fresh agricultural products must be controlled and guaranteed during transportation. The cold chain logistics is hence become inevitable. As to provide and integrate the logistics information, the cold chain logistics vehicle need to be upgraded with information accession and transmission. Some suggestions are listed:

- To instantly record the products receiving information at farmer site, a handhold device to input the information and transmit wirelessly to the server of the system is required.

- The transportation management functions include: products receiving and recording, warehouse entrance check and record, and report for transportation management.

- The storage management functions are similar as the warehouse management functions and include: warehouse receiving, automatic storage location assignment, load to storage location, and unload from 
storage location, lot split, storage location change, inventory check, and production releasing.

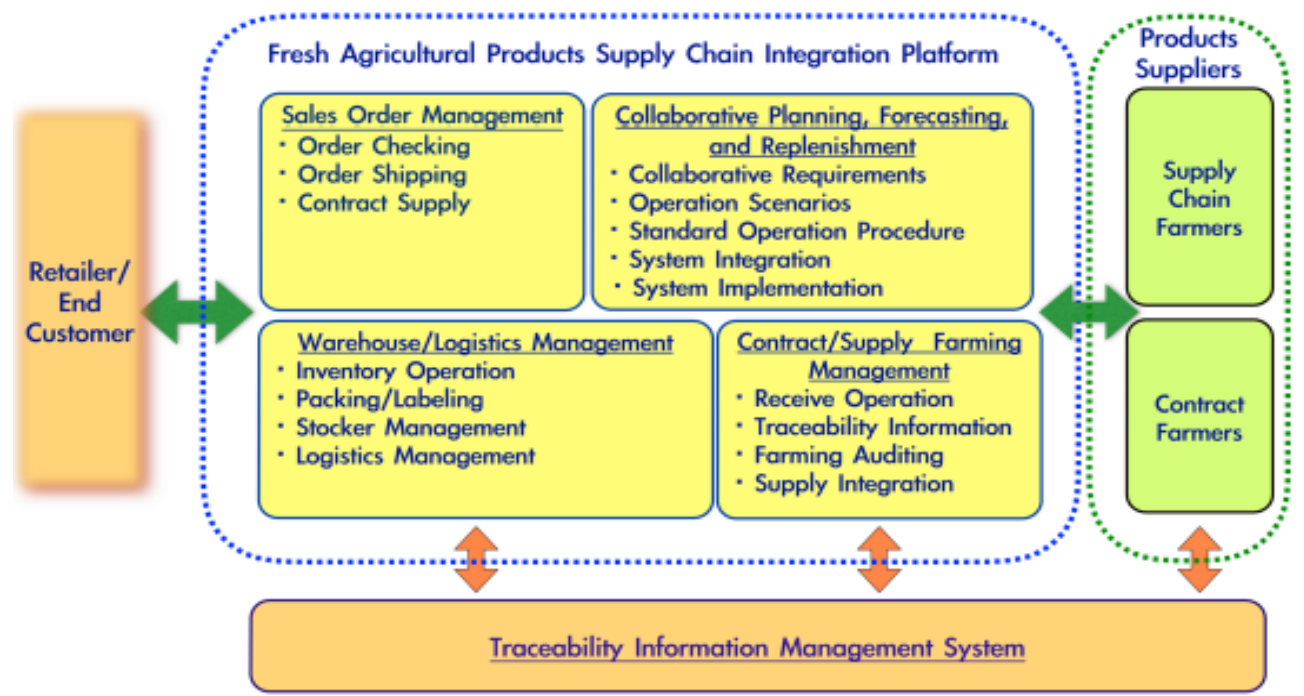

Figure 4. System integration architecture for the information management platform for traceability and logistics management of the fresh agricultural products supply chain.

\section{SUMMARY AND CONCLUSION}

The fresh agricultural products supply chain is reviewed and the logistics and system analysis for integrated information management platform are studied based on the project experiences in Tianjin. System infrastructure and architecture to minimize the unbalance of the supply-anddemand of fresh agricultural products are proposed in this paper. Integration of traceability along the supply chain, form the contract farming to the storage and logistics procedure, for food safety from farm to table are considered. The requirements are summarized by the MDBT approach to provide a service-oriented-architecture solution. Some issues on the efficient traceability data collection, integrated information platform, and logistics management through the fresh agricultural products are reviewed and suggested. With the proposed functional requirements and system analysis, the results of this paper can be fruitful for the further design of the fresh agricultural products logistics information management platform systems.

\section{ACKNOWLEDGMENT}

This work was financially supported by the Tianjin Administration of Foreign Affairs (project no. 20171200248).

\section{REFERENCES}

[1] G. Schiefer, "New technologies and their impact on the agri-food sector: an economists view," Comput. and Electron. in Agr., Vol. 43, no. 2, pp. 163-172, 2004.

[2] T. Moe, "Perspectives on traceability in food manufacture," Trends in Food Science \& Technology, Vol. 9, pp. 211-214, 1998.

[3] M. Varga and B. Csukas, "On the way toward the sector spanning agrifood process traceability," Agricultural Informatics, vol. 1, no. 1, pp. 8-18, 2010.
[4] L. U. Opara, "Traceability in agriculture and food supply chain: a review of basic concepts, technological implications, and future prospects," J. of Food Agric. Environ., vol. 1, no. 1, pp.101-106, 2003.

[5] X. Wang, D. Li, and L. Li, "Adding value of food traceability to the business: a supply chain management approach," Int. J. of Serv. Oper. and Informat., vol. 4, no. 3, pp. 232-257, 2009.

[6] T. Bosona and G. Gebresenbet, "Food traceability as an integral part of logistics management in food and agricultural supply chain," Food Control, vol. 33, pp. 32-48, 2013.

[7] C. G. Sørensena, S. Fountasb, E. Nashf, L. Pesonend, D. Bochtisa, S M. Pedersene, B. Bassoc, S. B. Blackmoreg, "Conceptual model of a future farm management information system," Comput. and Electron. in Agr., vol. 72, no. 1, pp. 37-47, 2010.

[8] T. Kelepouris, K. Pramatari, and G. Doukidis, "RFID-enabled traceability in the food supply chain,” Ind. Mana. Data Syst., vol., 107, no. 2, pp. 183-200, 2007.

[9] A. Regattieri, M. Gamberi, and R. Manzini, "Traceability of food products: General framework and experimental evidence," J. of Food Eng., vol. 81, no. 2, pp. 347-356, 2007.

[10] V. Manthou, A. Matopoulos, and M., "Vlachopoulou, Internet-based applications in the agri-food supply chain: a survey on the Greek canning sector," J. of Food Eng., vol. 70, no. 3, pp. 447-454, 2005.

[11] M. Li, J. P. Qian, X. T. Yang, C. H. Sun, and Z. T. Ji, "A PDA-based record-keeping and decision-support system for traceability in cucumber production," Comput. and Electron. in Agr., vol. 70, no. 1, pp.69-77, 2010.

[12] . N. Nambiar, "Trends in food packaging and manufacturing systems and technology," Trends Food Sci. Tech., vol. 21, no. 3, pp. 117-128, 2010.

[13] S. Kumaran, "Model Driven Enterprise," Proceedings of the Global Enterprise Application Integration Summit, pp. 166-180, Banf, Canada, 2004.

[14] S. Kumaran, P. Bishop, T. Chao, P. Dhoolia, P. Jain, R. Jaluka, H. Ludwig, A. Moyer, and A. Nigam, "Using a Model-Driven Transformational Approach and Service-Oriented Architecture for Service Delivery Management”, IBM System Journal, vol. 46, no. 3, pp. 513-529, July 2007.

[15] Y. C. Liu and H. M. Gao, "Development and Applications of Mobile Farming Information System for Food Traceability in Health 
Management," in Applied Computing in Medicine and Health, edited

by D. Al-Jumeily, A. Hussain, C. Mallucci, and C.Oliver, Elsevier, Aug. 2015, pp. 244-2 